\title{
A Circadian Rhythm in the Expression of PERIOD2 Protein Reveals a Novel SCN-Controlled Oscillator in the Oval Nucleus of the Bed Nucleus of the Stria Terminalis
}

\author{
Shimon Amir, Elaine Waddington Lamont, Barry Robinson, and Jane Stewart \\ Center for Studies in Behavioral Neurobiology, Department of Psychology, Concordia University, Montréal, Québec H4B 1R6, Canada
}

\begin{abstract}
Circadian rhythms in mammals are regulated not only globally by the master clock in the suprachiasmatic nucleus (SCN), but also locally by widely distributed populations of clock cells in the brain and periphery that control tissue-specific rhythmic outputs. Here we show that the oval nucleus of the bed nucleus of the stria terminalis (BNST-OV) exhibits a robust circadian rhythm in expression of the Period2 (PER2) clock protein. PER2 expression is rhythmic in the BNST-OV in rats housed under a light/dark cycle or in constant darkness, in blind rats, and in mice, and is in perfect synchrony with the PER2 rhythm of the SCN. Constant light or bilateral SCN lesions abolish the rhythm of PER 2 in the BNST-OV. Large abrupt shifts in the light schedule transiently uncouple the BNST-OV rhythm from that of the SCN. Re-entrainment of the PER2 rhythm is faster in the SCN than in the BNST-OV, and it is faster after a delay than an advance shift. Bilateral adrenalectomy blunts the PER2 rhythm in the BNST-OV. Thus, the BNST-OV contains circadian clock cells that normally oscillate in synchrony with the SCN, but these cells appear to require both input from the SCN and circulating glucocorticoids to maintain their circadian oscillation. Taken together with what is known about the functional organization of the connections of the BNST-OV with systems of the brain involved in stress and motivational processes, these findings place BNST-OV oscillators in a position to influence specific physiological and behavioral rhythms downstream from the SCN clock.
\end{abstract}

Key words: bed nucleus of the stria terminalis; oval nucleus; suprachiasmatic nucleus; PER2; circadian rhythm; rat

\section{Introduction}

The suprachiasmatic nucleus (SCN) of the hypothalamus is the primary circadian clock regulating daily rhythms in behavior and physiology in mammals (Klein et al., 1991). The cells of the SCN exhibit intrinsic circadian oscillations in gene expression and in electrical and metabolic activity (Inouye and Kawamura, 1979; Schwartz et al., 1980; Gillette and Reppert, 1987; Welsh et al., 1995; Reppert, 2000; Shearman et al., 2000; Beaulé et al., 2001; Reppert and Weaver, 2001), destruction of the SCN abolishes all circadian rhythms, and, most importantly, transplants of fetal SCN tissue, but not tissue from other brain regions, can restore circadian behavioral rhythms in SCN-ablated animals (Ralph et al., 1990; Aguilar-Roblero et al., 1992; LeSauter et al., 1996; Li and Satinoff, 1998; Sollars and Pickard, 1998). How the oscillations of the SCN are translated into behavioral and physiological rhythms is not well understood. A leading hypothesis is that the gating of circadian information into specific rhythmic outputs is mediated by tissue-specific subordinate oscillators that are entrained by the SCN clock (Yamazaki et al., 2000; Buijs and Kalsbeek, 2001; Bal-

Received 0ct. 2, 2003; revised Nov. 6, 2003; accepted Nov. 17, 2003.

This work was supported by grants from the Canadian Institutes of Health Research and the Fonds pour la Formation des Chercheurs et l'Aide à la Recherche.

Correspondence should be addressed to Shimon Amir, Center for Studies in Behavioral Neurobiology, Concordia University, SP-244, 7141 Sherbrooke Street West, Montréal, QC, Canada H4B 1R6. E-mail: amir@csbn.concordia.ca. D0I:10.1523/JNEUROSCI.4488-03.2004

Copyright $\odot 2004$ Society for Neuroscience $\quad$ 0270-6474/04/240781-10\$15.00/0 salobre, 2002; Reppert and Weaver, 2002; Schibler and SassoneCorsi, 2002; Hastings et al., 2003).

The bed nucleus of the stria terminalis (BNST) is a complex and neurochemically heterogeneous basal forebrain structure that modulates a wide range of physiological and motivational processes. These include, but are not limited to, neuroendocrine, autonomic, and behavioral responses to different types of stress and to drugs of abuse, ingestive behaviors, and reproductive and maternal behaviors (Fink and Smith, 1980; Casada and Dafny, 1991; Loewy, 1991; Gray, 1993; Davis et al., 1997; Van de Kar and Blair, 1999; Stefanova and Ovtscharoff, 2000; Erb et al., 2001; Nijsen et al., 2001; Walker et al., 2001; Figueiredo et al., 2003; Walker et al., 2003). Notably, many of the processes influenced by the BNST are under circadian control. Furthermore, there is anatomical and electrophysiological evidence that the BNST is linked to the SCN and that these structures exhibit synchronous rhythms in neural activity (Watts et al., 1987; Yamazaki et al., 1998; Leak and Moore, 2001). Such evidence, taken together with what is known about the functional organization of the connections of the BNST with systems of the brain involved in stress and motivational processes, places the BNST in a position to influence specific physiological and behavioral rhythms. To begin to explore this possibility, we asked first whether the BNST contains circadian clock cells that are controlled by the SCN. To this end, we studied the expression of the Period2 protein (PER2) in the BNST in rats. The rhythmic expression of PER2 is considered to be a defining feature of the molecular oscillators generating cir- 
cadian rhythms in mammalian cells, and analyses of the expression of Per2 mRNA and PER2 have been used to identify clock cells in both neural and non-neural tissues (Oishi et al., 1998; Zheng et al., 1999; Field et al., 2000; Nuesslein-Hildesheim et al., 2000; Bittman et al., 2003; Shieh, 2003).

\section{Materials and Methods}

Animals and housing. The experimental procedures followed the guidelines of the Canadian Council on Animal Care and were approved by the Animal Care Committee, Concordia University. Adult male Wistar rats (275-300 gm), bilaterally adrenalectomized Wistar rats (250-275 gm), and adult male CF-1 mice (25-30 gm) were purchased from Charles River (St. Constant, Québec). All animals had ad libitum access to food and water. Adrenalectomized rats were given saline solution $(0.9 \% \mathrm{NaCl})$ as a drinking fluid. Rats were housed individually in clear plastic cages equipped with running wheels. The cages were housed in ventilated, sound- and light-tight isolation chambers equipped with a computercontrolled lighting system (VitalView; Mini Mitter Co., Sunriver, OR). Each running wheel was equipped with a magnetic microswitch connected to a computer. Wheel-running activity data were recorded with VitalView software (Mini Mitter Co.) and analyzed with Circadia Software. Mice were housed three per cage in isolation chambers.

Surgery. Rats were anesthetized with a ketamine $(100 \mathrm{mg} / \mathrm{ml}) /$ xylazine $(20 \mathrm{mg} / \mathrm{ml})$ mixture given intraperitoneally $(1.5 \mathrm{ml} / \mathrm{kg})$. Electrolytic lesions aimed at the SCN (1.2 mm posterior to bregma; $1.9 \mathrm{~mm}$ lateral to the midline; $9.4 \mathrm{~mm}$ below the surface of the skull, at a $10^{\circ}$ angle) were made by passing $2 \mathrm{~mA}$ current for $15 \mathrm{sec}$ through stainless steel electrodes (0.28 $\mathrm{mm}$ in diameter), insulated except for the tip, using a Grass lesion maker (D.C. LM5A; Grass Instruments, West Warwick, RI). Neonatal enucleation was performed on 2- to 3-d-old male Wistar rat pups, under isoflurane anesthesia, by severing the optic nerve, muscle, and other connective tissues and removing the eyes.

Tissue preparation. Rats were injected with an overdose of sodium pentobarbital $(\sim 100 \mathrm{mg} / \mathrm{kg})$ and perfused intracardially with $300 \mathrm{ml}$ of cold saline $(0.9 \% \mathrm{NaCl})$ followed by $300 \mathrm{ml}$ of cold, $4 \%$ paraformaldehyde in a $0.1 \mathrm{~m}$ phosphate buffer, $\mathrm{pH}$ 7.3. Mice were perfused intracardially with $75 \mathrm{ml}$ of cold saline followed by $75 \mathrm{ml}$ of cold $4 \%$ paraformaldehyde. After perfusion, brains were postfixed in $4 \%$ paraformaldehyde and stored at $4^{\circ} \mathrm{C}$ overnight. Serial coronal brain sections $(50 \mu \mathrm{m})$ containing the SCN and BNST were collected from each animal using a vibratome.

Immunocytochemistry. Free-floating sections were washed in cold 50 mM Tris buffered saline (TBS), pH 7.6, and incubated at room temperature for $30 \mathrm{~min}$ in a quenching solution made of TBS and $3 \% \mathrm{w} / \mathrm{w}_{2} \mathrm{O}_{2}$. After the quenching phase, sections were rinsed in cold TBS and incubated for $1 \mathrm{hr}$ at room temperature in a preblocking solution made of $0.3 \%$ Triton X-100 in TBS (Triton-TBS), 3\% normal goat serum, and 5\% milk buffer. After the preblocking phase, sections were transferred directly into an affinity-purified rabbit polyclonal antibody raised against PER2 (ADI, San Antonio, TX) diluted 1:1000 with a solution of TritonTBS with 3\% normal goat serum in milk buffer. Sections were incubated with the primary antibody for $48 \mathrm{hr}$ at $4^{\circ} \mathrm{C}$. After incubation in the primary antibody, sections were rinsed in cold TBS and incubated for 1 $\mathrm{hr}$ at $4^{\circ} \mathrm{C}$ with a biotinylated anti-rabbit IgG made in goat (Vector Labs, Burlingame, CA), diluted 1:200 with Triton-TBS with 2\% normal goat serum. After incubation with secondary antibody, sections were rinsed in cold TBS and incubated for $2 \mathrm{hr}$ at $4^{\circ} \mathrm{C}$ with an avidin-biotin-peroxidase complex (Vectastain Elite ABC Kit; Vector Labs). After incubation with the $\mathrm{ABC}$ reagents, sections were rinsed with cold TBS, rinsed again with cold 50 mm Tris- $\mathrm{HCl}, \mathrm{pH}$ 7.6, and again for $10 \mathrm{~min}$ with $0.05 \% 3,3^{\prime}$ diaminobenzidine (DAB) in $50 \mathrm{~mm}$ Tris- $\mathrm{HCl}$. Sections were then incubated on an orbital shaker for $10 \mathrm{~min}$ in $\mathrm{DAB} /$ Tris- $\mathrm{HCl}$ with $0.01 \% \mathrm{H}_{2} \mathrm{O}_{2}$ and $8 \% \mathrm{NiCl}_{2}$. After this final incubation, sections were rinsed in cold TBS, wet-mounted onto gel-coated slides, dehydrated through a series of alcohols, soaked in Citrisolv (Fisher Scientific, Houston, TX), and coverslipped with Permount (Fisher). Blocking experiments performed by adding the PER2 peptide $(1 \mathrm{mg} / \mathrm{ml}$ in PBS, $\mathrm{pH} 7.4$, with $0.02 \%$ sodium

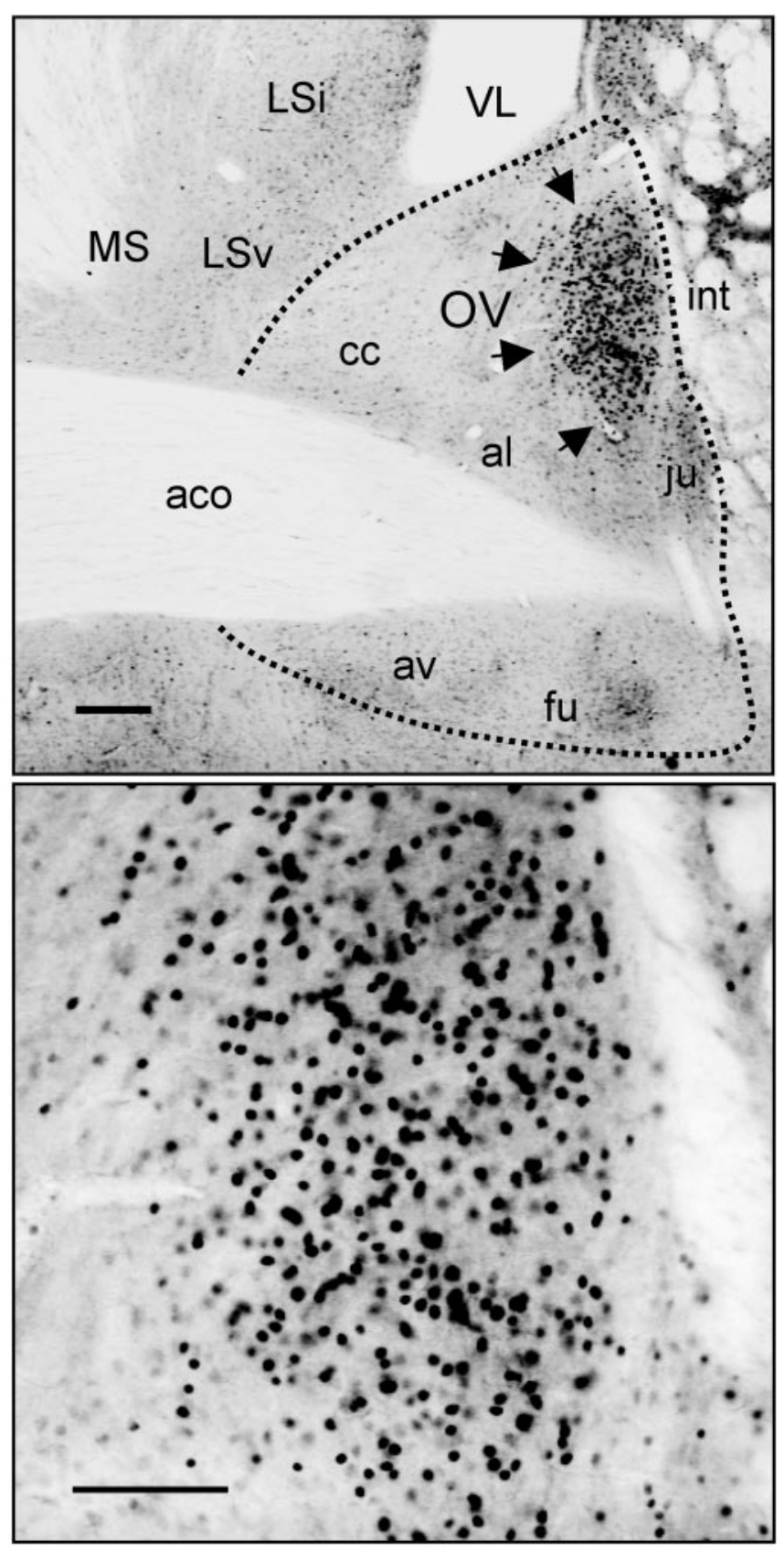

Figure 1. Expression of PER2 immunoreactivity in the BNST-OV. Top, Photomicrograph of a coronal brain section containing the BNST from a rat killed at ZT12. PER2 immunoreactivity is concentrated in the BNST-OV (marked by the black arrows). Expression in all other subdivisions of the BNST is exceedingly low. Scale bar, $200 \mu \mathrm{m}$. Bottom, High magnification of BNST-OV showing PER2 immunostaining. Scale bar, $100 \mu \mathrm{m}$. aco, Anterior commissure; av, anteroventral BNST; fu, fusiform nucleus of the BNST; al, anterolateral BNST; ju, juxtacapsular nucleus of the BNST; cc, anterolateral BNST central core; int, internal capsule; MS, medial septal nucleus; Lsv, ventral lateral septal nucleus; Lsi, intermediate part of the lateral septal nucleus; VL, lateral ventricle.

merthiolate, diluted 1:100) to the primary incubation solution prevented PER2 staining.

Data analysis. Stained brain sections were examined under a light microscope, and images were captured using a Sony XC-77 video camera, a Scion LG-3 frame grabber, and NIH Image (v1.63) software. Cells immunopositive for PER2 were counted manually using the captured images. For analysis, the mean number of PER2 immunoreactive cells per region was calculated for each animal from the counts of six unilateral 
a
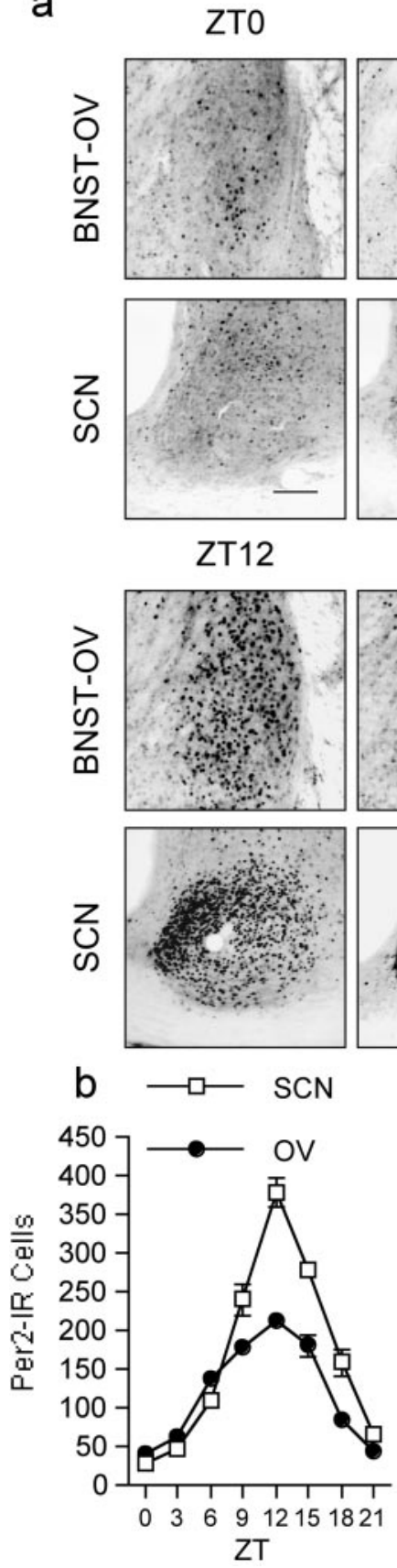

Figure 2. Synchronous rhythmic expression of PER2 in the BNST-OV and SCN. $a$, Photomicrographs showing examples of PER2 immunostaining in the BNST-OV and SCN from rats housed under a $12 \mathrm{hr}$ LD cycle and killed at different ZTs (ZT0, lights on; ZT12, lights off). Scale bar, $200 \mu \mathrm{m} . b$, Mean \pm SEM number of PER2-immunoreactive (Per2-IR Cells) nuclei in the SCN and BNST-OV of rats killed at different ZTs ( $n=4$ per time point). c, Mean \pm SEM number of PER2-immunoreactive nuclei in the SCN and BNST-OV of rats that were housed in constant darkness and killed at different CTs ( $n=4$ per time point). $d$, Mean \pm SEM number of PER2-immunoreactive nuclei in the SCN and BNST-OV of adult rats that were enucleated during the neonatal period and killed at CT0 or CT12 ( $n=4$ per time point).

images showing the highest number of labeled nuclei. Differences between groups were revealed with ANOVA. Significance threshold was set at 0.05 for all analyses.

\section{Results}

Synchronous rhythms in PER2 expression in the SCN and oval nucleus of the BNST

We first examined the expression of PER2 in the BNST and SCN of rats that were housed under a $12 \mathrm{hr}$ light/dark (LD) cycle (300 lux at cage level) for at least $20 \mathrm{~d}$ and killed at one of eight equally spaced zeitgeber times (ZTs) (ZT0 denotes time of light on) over the day and night $(n=4$ per time point). Analysis of PER 2 expression in the BNST revealed dense nuclear staining within the oval nucleus (BNST-OV), an anatomically circumscribed and neurochemically distinct structure located in the dorsal lateral region of the BNST (Dong et al., 2001) (Fig. 1). PER2 expression within the BNST-OV was strongly rhythmic, maximal at the beginning of the dark phase of the entraining photocycle, at ZT12, and minimal at ZT0, the onset of the light phase (Fig. $2 a, b$ ). In all other subregions of the BNST, immunostaining for PER2 was exceedingly low at all times. The daily pattern of PER2 expression in the BNST-OV was identical to that seen in the SCN (Fig. 2a,b), demonstrating that under entrained conditions the BNST-OV and SCN exhibit synchronous rhythms in expression of PER2.

\section{Synchronous rhythms in PER2} expression in the SCN and BNST-OV persist in constant darkness and in blind rats

The finding that the BNST-OV and SCN exhibit synchronous daily rhythms in expression of PER2 suggests strong coupling between the SCN clock and putative clock cells in the BNST-OV. Such coupling may be mediated intrinsically, independent of the light cycle, or it may be the result of a common effect of the light cycle on Per2 gene expression in the two structures. This latter possibility is consistent with evidence that PER2 expression in the SCN is synchronized by the light cycle (Field et al., 2000), and by the finding that the BNST receives input from the eyes (Itaya et al., 1981; Cooper et al., 1994). To exclude the role of the photocycle, we assessed the expression of PER2 immunoreactivity in rats that were housed in constant darkness (DD) for $3 \mathrm{~d}$ and killed at one of eight equally spaced circadian times (CTs) [CT12 denotes the onset of daily activity (subjective night) under DD conditions] during the subjective day or night $(n=4$ per time point). In addition, to examine the role of the eyes themselves (Beaule and Amir, 2003; Lee et al., 2003), we assessed the expression of PER2 in BNST-OV and SCN of adult blind rats that were enucleated during the neonatal period. PER2 expression in the BNST-OV of DD housed rats was strongly rhythmic, peaking at the beginning of the subjective night, at CT12, and in complete synchrony with the rhythm of PER2 expression in the SCN (Fig. 2c). Similarly, levels of PER2 expression in the SCN and BNST-OV of blind rats were high at CT12 and low at CT0 (Fig. 2d) and similar in mag- 
nitude to those seen in sighted rats at the same circadian times (compare Fig. 2c). Thus, the BNST-OV and SCN exhibit synchronous rhythms in PER2 expression under constant conditions in the absence of photic time cues.

\section{Synchronous PER2 expression in the SCN and the BNST-OV of the mouse} To determine whether the rhythm in PER2 expression in the BNST-OV is species specific, we assessed the expression of PER2 in mice that were housed under a $12 \mathrm{hr}$ LD cycle and killed at ZT0 or ZT12. Consistent with our finding in rats, in both the SCN and BNST-OV of light-entrained mice, the expression of PER2 was high at ZT12 and low at ZT0 (Fig. 3), suggesting synchronous oscillations.

\section{PER2 oscillation in the BNST-OV depends on the functional integrity of the SCN}

The subordinate nature of circadian clocks outside the SCN is evident from the finding that the oscillations in clock gene expression in most brain and peripheral tissues are not self-sustaining and dampen after a few days in vitro (Yamazaki et al., 2000; Abe et al., 2002; Balsalobre, 2002). Furthermore, it has been shown that SCN lesions that abolish circadian activity rhythms abolish circadian oscillations in Per gene expression in the brain and periphery in rats and in mice, in vivo (Oishi et al., 1998; Sakamoto et al., 1998; Wakamatsu et al., 2001). To study the role of the SCN in the control of PER2 oscillations in the BNST-OV, we assessed the expression of PER2 immunoreactivity in rats with bilateral electrolytic SCN lesions. To verify the effectiveness of the lesion, all of the lesioned rats were housed in cages equipped with running wheels, under a $12 \mathrm{hr}$ LD cycle, and their activity rhythms were monitored continuously for at least $60 \mathrm{~d}$. Of the 25 lesioned rats, 15 became permanently behaviorally arrhythmic (Fig. 4a). Histological inspection of brain sections from these arrhythmic rats revealed that all sustained considerable bilateral SCN damage. Of these, two rats had complete bilateral lesion that extended the entire length of the paired nuclei. All other arrhythmic rats sustained partial SCN damage that varied both in size and in location. In all arrhythmic rats the lesion extended from the SCN both laterally to the central part of the anterior hypothalamus and dorsally to the subparaventricular zone (Fig. $4 b$ ). The remaining 10 lesioned rats did not become arrhythmic and were able to entrain to the LD cycle despite sustaining considerable damage in the SCN and surrounding tissues (Fig. $4 a, b$ ). In these lesioned but behaviorally rhythmic rats, PER2 expression in the BNST-OV was high at ZT12 and low at ZT0 (Fig. 4c). This pattern of expression is identical to that seen in intact entrained rats at these times (Fig. 2). In contrast, PER2 expression in the BNST-OV of the behaviorally arrhythmic lesioned rats did not vary as a function of time and was at an intermediate level. These results suggest that the rhythm in PER2 expression in the BNST-OV depends on the functional integrity of the SCN clock as assessed by its ability to drive circadian locomotor activity rhythms. They also indicate that although the SCN clock appears to control the daily oscillation in PER2 expression in the BNST-OV, it is not required for the local expression of the PER2 protein, per se.

\section{Constant-light-induced behavioral arrhythmicity blunts PER2 oscillations in SCN and BNST-OV}

As is the case with bilateral SCN lesions, prolonged housing in constant light (LL) abolishes circadian activity and temperature rhythms in rats (Edelstein et al., 1995; Edelstein and Amir, 1999). Furthermore, it has been found recently that LL-induced behavioral arrhythmicity is associated with blunting of the PER2 rhythm in the SCN (Beaulé et al., 2003; Sudo et al., 2003), a finding that is consistent with the idea that the behavioral effects of LL are mediated, at least in part, by a disruption of the molecular oscillation of the SCN clock. To study the importance of the SCN clock itself in the control of PER2 oscillations in the BNST$\mathrm{OV}$, we assessed the expression of PER2 immunoreactivity in the BNST-OV of rats that were housed in LL and displayed behavioral arrhythmicity for at least $40 \mathrm{~d}$ (Fig. $5 a$ ). PER2 expression in both the SCN and BNST-OV of these arrhythmic rats was blunted, and there were no significant variations in expression levels between the four equally spaced time points used for the analysis (Fig. 5b,c) (ANOVA: SCN, $F_{(3,10)}=0.76, p=0.54$; $\left.\mathrm{BNST}-\mathrm{OV}, F_{(3,10)}=0.379, p=0.77\right)$. The finding that prolonged LL housing abolishes PER2 rhythmicity both in the SCN and in the BNST-OV underscores the importance of the SCN clock in the control of the rhythm of PER2 expression in the BNST-OV.

\section{PER2 oscillation in the left and right BNST-OV after unilateral SCN lesion}

Several different mechanisms could mediate the effect of the SCN on PER2 oscillations in the BNST-OV. The rhythm in PER2 could be regulated by signals communicated from the SCN via neural projections (Watts et al., 1987). Alternatively, the rhythm may be regulated by a diffusible factor released from the SCN or by oscillating endocrine signals, such as corticosterone (Silver et al., 1996; Oishi et al., 1998; Balsalobre et al., 2000a). Finally, it may be under the control of one or more behavioral states that, themselves, are under circadian control, such as locomotor activ- 


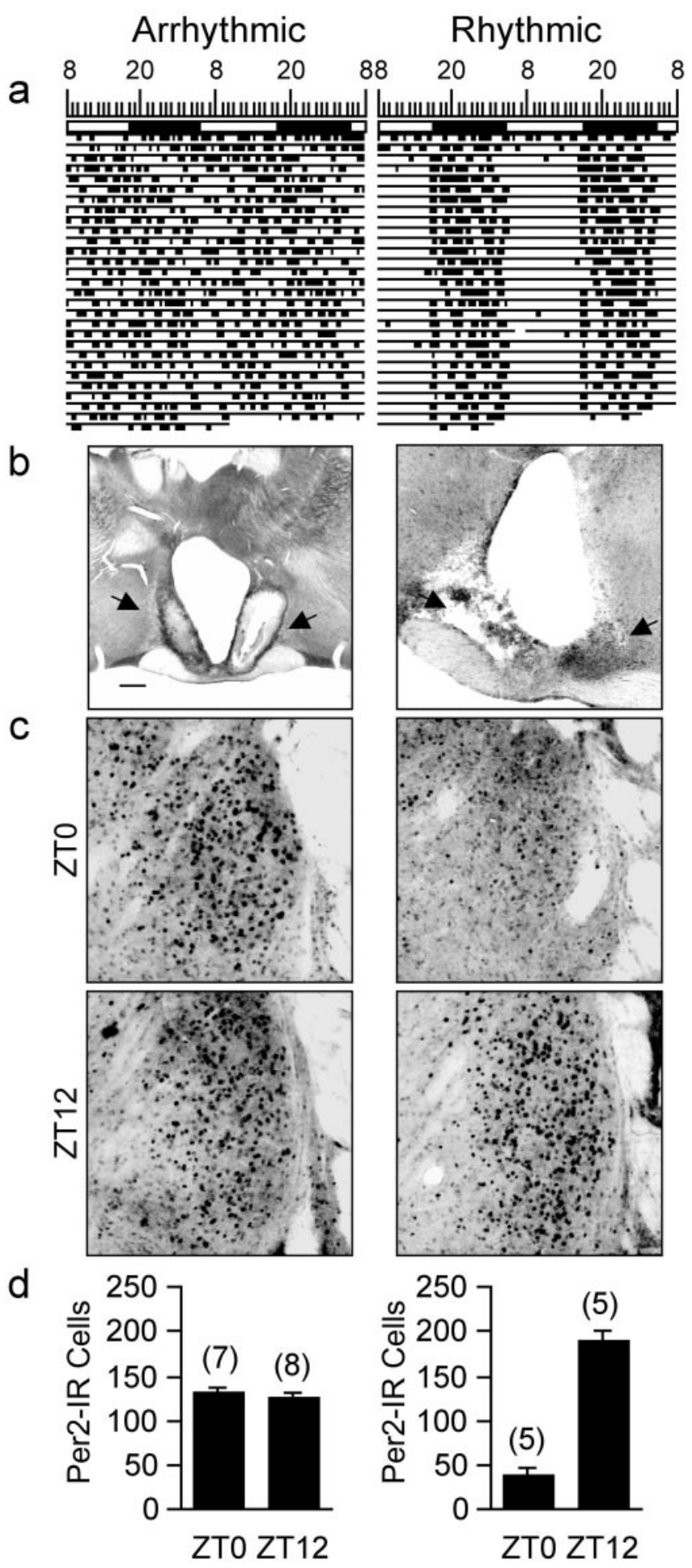

Figure 4. Bilateral SCN lesions that disrupt circadian activity rhythms abolish PER2 oscillations in the BNST-OV.a, Representative double-plotted actograms of wheel-running activity in an SCN-lesioned arrhythmic rat (left) and in a lesioned rat that remained rhythmic (right). The rats were housed under a $12 \mathrm{hr} L D$ cycle. The vertical marks indicate periods of activity of at least 10 wheel revolutions per $10 \mathrm{~min}$. Successive days are plotted from top to bottom. $b$, Photomicrographs showing the largest extent of the SCN lesions (arrows) of rats whose actograms are shown in $a$. Scale bar, $200 \mu \mathrm{m}$. c, Photomicrographs showing examples of PER2 immunostaining in the BNST-OV from SCN-lesioned, arrhythmic rats (left) and from lesioned, rhythmic rats (right) as a function of ZT. Magnification, 20X.d, Mean \pm SEM number of PER2immunoreactive nuclei in the BNST-OV of SCN-lesioned arrhythmic rats (left) and of lesioned, rhythmic rats (right) as a function of ZT. The numbers in brackets indicate the number of rats per time point. ity or feeding (Mrosovsky, 1996; Wakamatsu et al., 2001). To begin to explore the role of neural connections as well as to exclude the role of activity, we assessed the expression of PER2 immunoreactivity separately in the left and right BNST-OV in behaviorally rhythmic rats bearing a unilateral SCN lesion. Neural connections between the SCN and some of its targets are lateralized (de la Iglesia et al., 2003). Accordingly, we hypothesized that if the rhythm in expression of PER2 in the BNST-OV depends on neural connections from the SCN, then the rhythm in expression of PER2 in the BNST-OV ipsilateral to the lesion would be attenuated and different from that in the contralateral side. Alternatively, if the rhythm of activity is the critical entraining agent, then PER2 expression in the ipsilateral and contralateral BNST-OV should not differ.

All unilateral SCN-lesioned rats $(n=12)$ exhibited stable photic entrainment of wheel-running activity rhythms and temporally appropriate levels of PER2 expression in the intact SCN (Fig. 6a). Furthermore, both the ipsilateral and contralateral BNST-OV showed a daily pattern of PER2 expression, with lower levels at ZT0 and higher levels at ZT12 (Fig. 6b,c). The magnitude of the daily difference, however, was blunted on the lesioned side. At ZT0, PER2 expression in the BNST-OV ipsilateral to the lesioned SCN was significantly greater $(p<0.001)$ than that in the contralateral side, whereas at ZT12, expression in the ipsilateral BNST-OV was significantly lower than that in the contralateral BNST-OV $(p<0.001)$. These results suggest that normal oscillations in PER2 expression in the BNST-OV depend, at least in part, on ipsilateral neural input from the SCN. Furthermore, the finding that unilateral SCN lesions attenuated the rhythm in PER2 expression in the ipsilateral BNST-OV, but had no effect on activity rhythms, excludes the involvement of activity, per se, in the regulation of PER2 expression in the BNST-OV.

\section{Uncoupling of PER2 expression between the SCN and} BNST-OV after acute shifts in the entraining light cycle Abrupt changes in the entraining light schedule alter the phase relationship between the $\mathrm{SCN}$ clock and subordinate clocks in the rest of the brain and periphery (Yamazaki et al., 2000; Abe et al., 2002). To further study the nature of the coupling between the SCN and BNST-OV, we assessed the expression of PER2 in LD housed rats that were subjected to an abrupt $8 \mathrm{hr}$ advance or $8 \mathrm{hr}$ delay in the onset of the entraining light cycle (Fig. 7a). PER2 was assessed in groups of rats ( $n=4$ per group) that were killed 2,4 , 6 , or $8 \mathrm{~d}$ after the imposed shift, at the new ZT12. The levels of PER2 in the SCN and BNST-OV in the shifted rats at the new ZT12 were compared with levels at ZT12 in entrained control rats. In rats subjected to an $8 \mathrm{hr}$ advance of light onset, PER2 expression in the SCN returned to the high levels expected at ZT12 after $6 \mathrm{~d}$, whereas in the BNST-OV, PER2 expression returned to the expected high levels after $8 \mathrm{~d}$ (Fig. $7 b$ ). After an $8 \mathrm{hr}$ delay in the time of light onset, PER2 expression in the SCN was at the expected high levels on day 2 and in the BNST-OV on day 6 (Fig. 7c). These results demonstrate that large shifts in the entraining light cycle are attended by sequential changes in the phase of expression of PER2 in the SCN and BNST-OV, consistent with the hypothesis that the SCN synchronizes the BNST-OV rhythm. They also show that such shifts in the light cycle disrupt the synchrony in PER2 expression between the SCN and BNST-OV. The duration of this disruption depends on the direction of the shift in the light cycle, with overall longer desynchrony seen after an advance than a delay shift. 
PER2 oscillation in the SCN and BNST$\mathrm{OV}$ after bilateral adrenalectomy

Basal secretion of glucocorticoid hormones from the adrenal glands follows a circadian rhythm that is under the control of the SCN clock (Szafarczyk et al., 1983). The adult SCN does not contain glucocorticoid receptors, and therefore it is unlikely that glucocorticoid hormones are involved in the regulation of clock gene expression in the SCN (Rosenfeld et al., 1988, 1993). In contrast, most peripheral tissues express glucocorticoid receptors, and administration of a synthetic glucocorticoid, dexamethasone, has been shown to induce Per gene expression in mouse liver, in vivo, and in cultured rat-1 fibroblasts (Balsalobre et al., 2000a,b, 2002), suggesting that circulating glucocorticoids regulate Per gene expression in some peripheral tissues. Glucocorticoid receptors are expressed in the BNST (Lechner and Valentino, 1999), and corticosterone has been shown to modulate neuropeptide gene expression in the BNST (Makino et al., 1994; Pompei et al., 1995; Watts and Sanchez-Watts, 1995). To begin to study the possibility that circulating glucocorticoids are involved in the control of PER2 in the BNST-OV, we assessed the expression of PER2 in the SCN and BNST-OV of bilaterally adrenalectomized (ADX) and sham-operated rats. All of the operated rats were housed in isolation boxes and maintained under a 12 hr LD cycle for at least 3 weeks before use. As expected, bilateral adrenalectomy had no effect on PER2 expression in the SCN (Fig. 8). In contrast, the rhythm in PER2 in the BNST-OV was blunted in the ADX rats $\left(F_{(3,19)}=1.24 ; p=0.32\right)$. PER2 expression in the BNST-OV in these rats remained at an intermediate level, suggesting that removal of the adrenals had a selective effect on the rhythm of PER2 but did not affect basal expression of PER2.

\section{Discussion}

The finding that many brain and peripheral tissues exhibit circadian oscillations in clock gene expression has led to the hypothesis that circadian rhythms in mammals are regulated not only globally by the master SCN clock, but also locally by widely distributed populations of subordinate clock cells that control tissue-specific rhythmic outputs (Schibler and Sassone-Corsi, 2002; Hastings et al., 2003). Contrary to the SCN clock, oscillators outside the SCN are not self-sustaining and lose their rhythmicity after a few days when studied in isolated tissue in vitro and after SCN lesions in vivo. It has been proposed that both neural and endocrine pathways under the control of the SCN drive the rhythm and set the phase of these peripheral oscillators (Sakamoto et al., 1998; Yamazaki et al., 2000; Abe et al., 2002; Balsalobre, 2002; Kalsbeek and Buijs, 2002; Schibler and Sassone-Corsi, 2002; Bittman et al., 2003; Hastings et al., 2003; Kriegsfeld et al., 2003).

In the present study we found that neurons in the BNST-OV, a distinct subregion of the BNST, exhibit a robust daily rhythm in expression of PER2, consistent with the hypothesis that the BNST contains circadian clock cells that might play a role in local control of circadian rhythms. The expression of PER2 was rhythmic in the BNST-OV in rats housed under a LD cycle or in constant darkness, in blind rats, and in mice, emphasizing the ubiquitous nature of this region-specific molecular oscillation. Most importantly, in both rats and mice, the rhythm in PER2 expression in the BNST-OV was in synchrony with the PER2 rhythm in the SCN. Interestingly, studies in hamsters (Yamazaki et al., 1998) and in rats (Abe et al., 2002) have shown that the phase of the oscillations in neural activity and clock gene expression in most other brain regions is distinct from the phase in the SCN. The finding that the BNST-OV and SCN exhibit synchronous rhythms in PER2 expression underscores the unique nature of the coupling between clock cells in the SCN and BNST and is consistent with the proposed role of the BNST in the gating of circadian information.

The rhythm in PER2 in the BNST-OV was eliminated by lesions of the SCN that abolished circadian activity rhythms and by constant-light housing that disrupts circadian activity rhythms and the oscillation in PER2 expression in the cells of the SCN 
ZTO
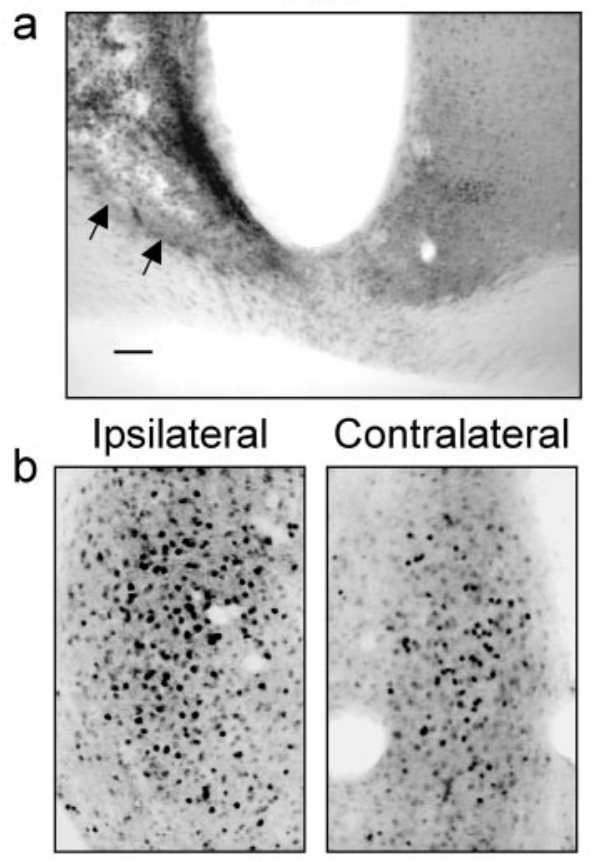
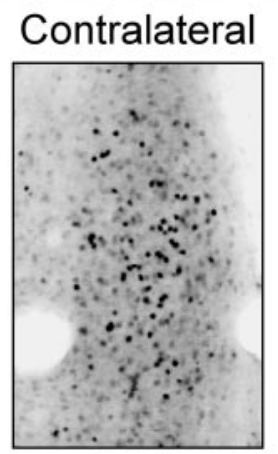
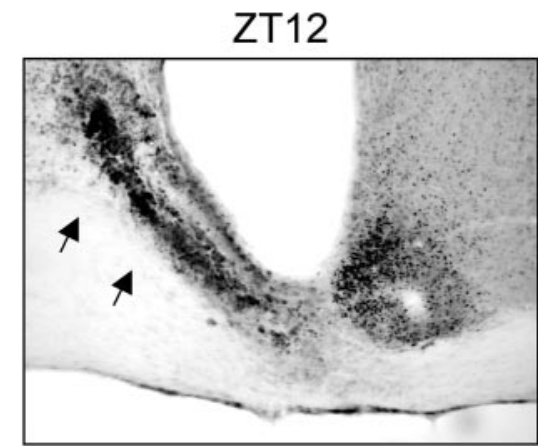

Ipsilateral
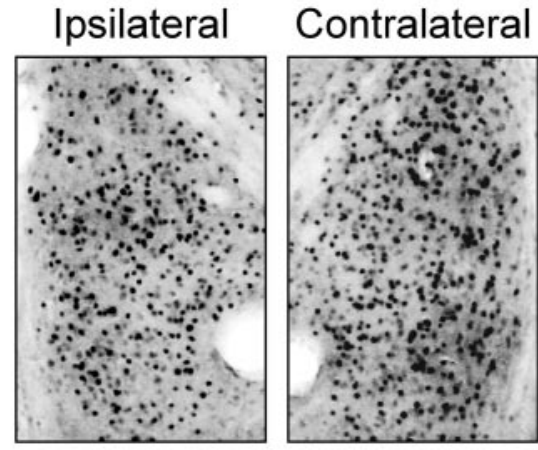

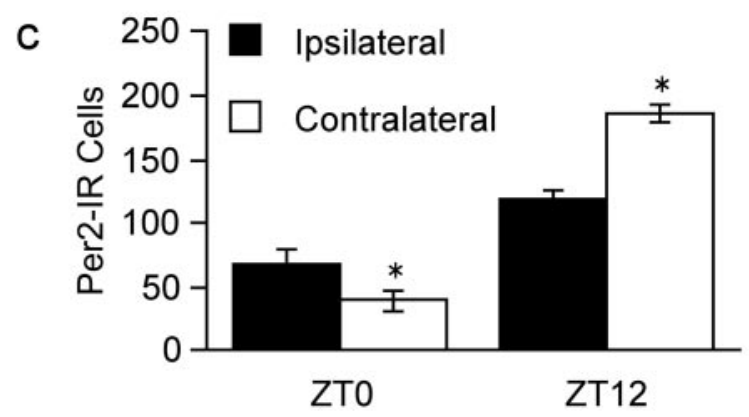

Figure 6. PER2 expression in the BNST-OV after unilateral SCN lesion. $a$, Photomicrographs showing examples of unilateral SCN lesions (arrows) in rats killed at ZT0 or ZT12. PER2 expression in the intact SCN is low at ZT0 and high at ZT12. Scale bar, $100 \mu \mathrm{m}$. $b$, Photomicrographs showing examples of PER2 immunoreactivity in the BNST-OV ipsilateral and contralateral to the lesioned SCN. Magnification, $20 \times$. c, Mean \pm SEM number of PER2-immunoreactive nuclei in the ipsilateral and contralateral BNST-OV as a function of ZT. Asterisks indicate significant differences from the ipsilateral side ( $p<0.05 ; n=5-7$ per time point).

structures it was faster after a delay than after an advance shift in the light cycle. These findings demonstrate that shifts in the light schedule transiently disrupt the synchrony between the PER2 rhythm in the SCN and that seen in the BNST-OV. Such disruptions in the relationship between the phase of the SCN clock and subordinate clocks could lead to internal desynchronization among specific behavioral and physiological rhythms and could explain the disruptive physiological and behavioral symptoms associated with travel across time zones and shift work (Abe et al., 2002; Reddy et al., 2002). Interestingly, restricted feeding schedules, which entrain circadian activity rhythms via SCN-independent clocks (Stephan et al., 1979), have also been shown to disrupt coupling between the SCN and other brain and peripheral oscillators (Damiola et al., 2000; Stokkan et al., 2001). Neurons in the BNST-OV are sensitive to food restriction (Carr et al., 1998; Carr and Kutchukhidze, 2000) and are activated by treatment with anorectic agents (Bonaz et al., 1993; Li and Rowland, 1995; Day et al., 1999), suggesting the intriguing possibility that oscillations of cells of the BNST-OV might be regulated directly by food-related stimuli.

The BNST-OV is responsive to corticosterone (Makino et al., 1994; Pompei et al., 1995; Watts and Sanchez-Watts, 1995), and it has been shown that glucocorticoids can induce clock gene expression in peripheral tissues (Balsalobre et al., 2000b). The results of our last experiment showing that removal of the adrenal glands blunts the rhythm in PER2 expression in the BNST-OV, although not in the SCN, strongly suggest a role for adrenal glucocorticoid hormones in the control of PER2 oscillations in the BNST-OV. More-

without affecting the anatomical integrity of the SCN (Beaule et al., 2003). Thus, the oscillations in PER2 in the BNST-OV depend on the functional integrity of the SCN clock, consistent with other findings on the effect of SCN lesions on rhythms of Per genes in the brain and periphery in rats and mice (Sakamoto et al., 1998; Wakamatsu et al., 2001). Interestingly, unilateral lesions of the SCN that were without an effect on circadian activity rhythms also influenced the PER2 rhythm in the BNST-OV; however, only the rhythm ipsilateral to the lesioned side was attenuated. This finding argues against the importance of activity rhythms, per se, in the control of PER2 oscillation in the BNST-OV and demonstrates that transmission of information from the SCN to the BNST-OV is dependent at least in part on ipsilateral neural connections.

It has been shown previously that abrupt changes in the entraining light schedule disrupt the normal phase relationship between the SCN and circadian oscillators in the brain and periphery (Yamazaki et al., 2000; Abe et al., 2002). In our experiments we found that entrainment of the PER2 rhythm to a shifted light cycle was faster in the SCN than in the BNST-OV and that in both over, and consistent with other evidence (Rosenfeld et al., 1993; Balsalobre et al., 2000b), they exclude a role for circulating corticosteroids in the regulation of clock gene expression in the SCN. Finally, and most significantly, the finding that removal of the adrenals blunts the rhythm in PER2 in the BNST-OV suggests that although neural pathways from the SCN are necessary for circadian regulation of PER2 expression in this region, other factors, in this case adrenal hormones, that normally oscillate in a circadian manner play an equally important role.

Most cells of the BNST-OV express the neurotransmitter, GABA (Sun and Cassell, 1993), suggesting that the rhythm in PER2 expression seen in the BNST-OV may be associated with oscillations in local GABAergic cell firing. Interestingly, GABA is the primary transmitter in the SCN (Moore and Speh, 1993; Moore et al., 2002), where it has been implicated in the synchronization among individual clock cells as well in the transmission of circadian information from the SCN (Moore and Speh, 1993; Liu and Reppert, 2000; Buijs and Kalsbeek, 2001; Kalsbeek and Buijs, 2002; Moore et al., 2002). Furthermore, the BNST-OV contains several neuropeptides, including corticotropin- 


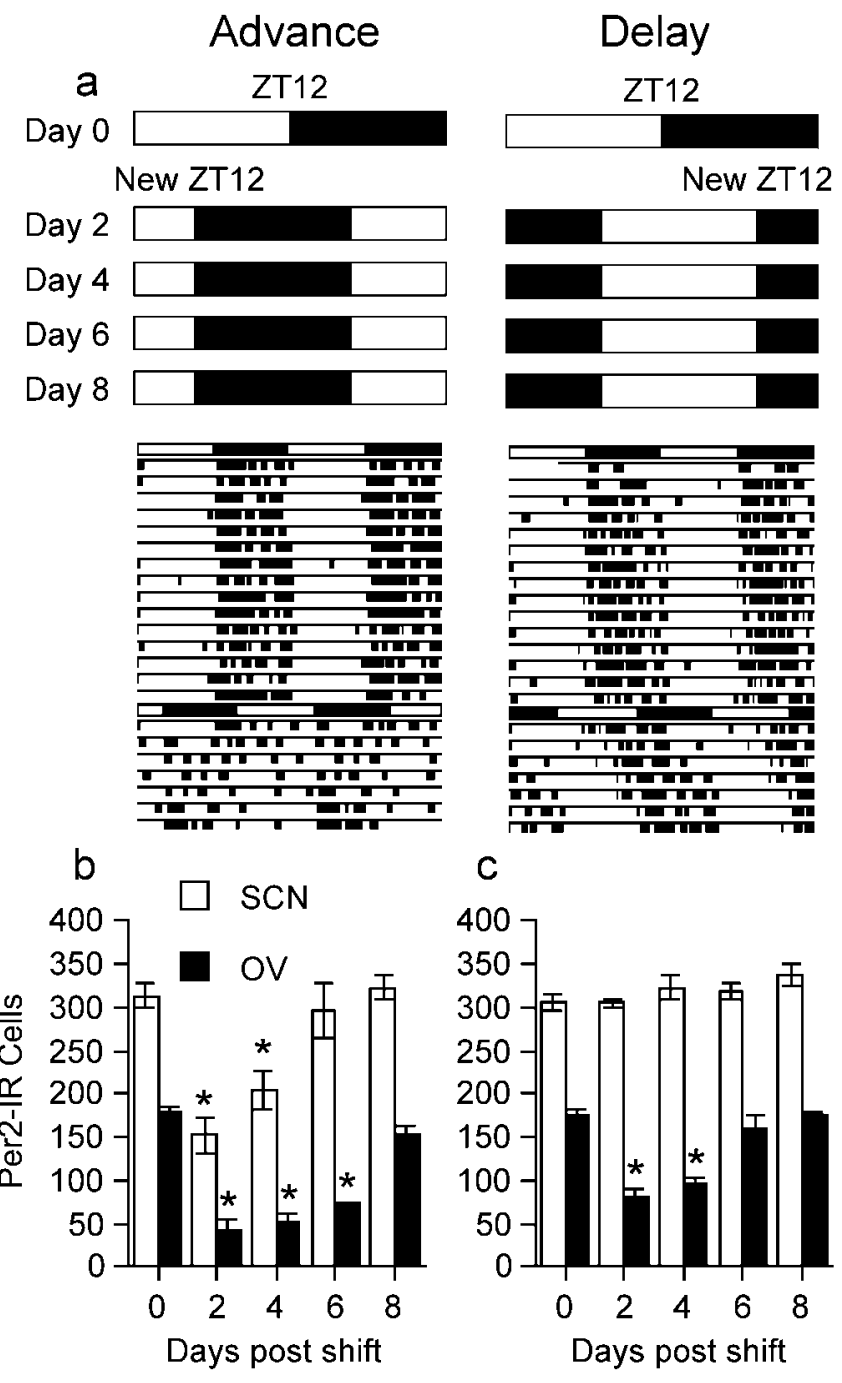

Figure 7. Uncoupling between PER2 expression in the SCN and BNST-OV after a shift in the light cycle. $a$, Schematic representation of the experimental design. The rats were entrained to a $12 \mathrm{hr} L \mathrm{D}$ cycle. The onset of light was then advanced or delayed by $8 \mathrm{hr}$, and rats were killed 2 , 4,6, or $8 \mathrm{~d}$ later at the new ZT12. Representative actograms of rats from the advance and delay groups killed $8 \mathrm{~d}$ after the shift are shown. $b$, Mean \pm SEM number of PER2-immunoreactive nuclei in the SCN and BNST-OV of rats killed at ZT12 without a shift (day 0) or 2, 4, 6, or $8 \mathrm{~d}$ after an advance shift at the new ZT12. c, Mean \pm SEM number of PER2-immunoreactive nuclei in the SCN and BNST-OV of rats killed at ZT12 without a shift (day 0) or 2, 4, 6, or $8 \mathrm{~d}$ after a delay shift at the new ZT12. Asterisks indicate significant difference from day 0 for each brain area.

releasing hormone $(\mathrm{CRH})$, enkephalin, neurotensin, somatostatin, and dynorphin (Dong et al., 2001). In preliminary studies we failed to observe any significant staining for PER2 in CRHimmunoreactive cells in the BNST-OV, whereas cells that expressed enkephalin immunoreactivity also contained PER2. The enkephalin cells of the BNST-OV have been shown to be activated by certain types of stress stimuli, including immune and osmotic stimuli, and by amphetamine injections (Watts and Sanchez-Watts, 1995; Day et al., 1999, 2001; Kozicz, 2002; Engstrom et al., 2003). It will be of interest, therefore, to determine whether such stimuli are capable of altering PER2 expression in the BNST-OV and thereby have an influence on specific, locally controlled circadian rhythms.

The BNST is involved in the modulation of physiological and behavioral processes that are known to be under circadian control, and it is linked both anatomically and functionally with the

\section{SCN}
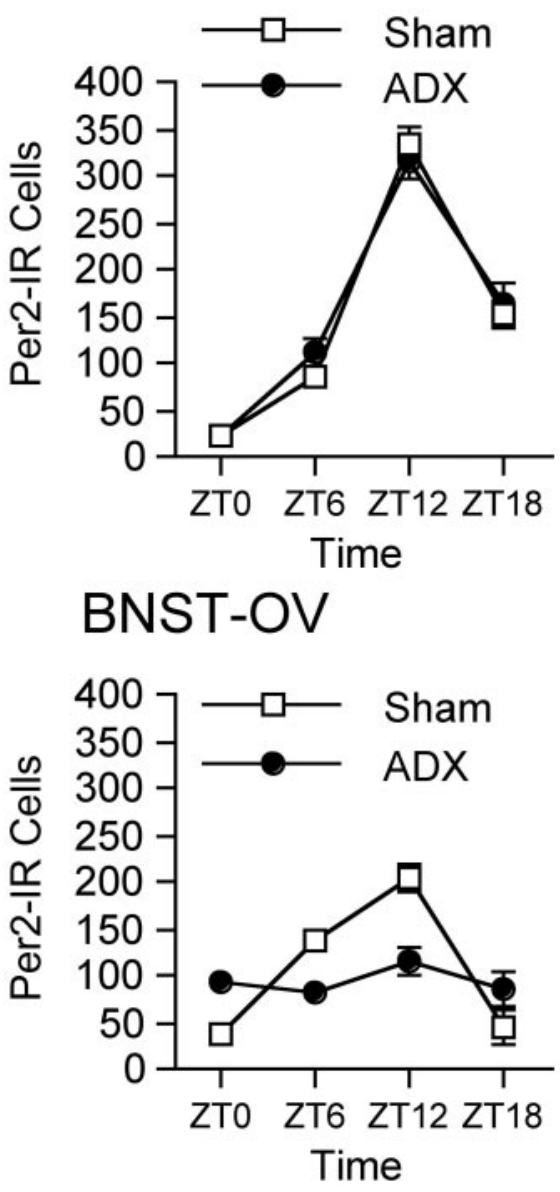

Figure 8. Effect of adrenalectomy on PER2 expression in the SCN and BNST-OV. Mean \pm SEM number of PER2-immunoreactive nuclei in the SCN (top) and BNST-OV (bottom) of adrenalectomized and sham-operated rats as a function of $Z T$ ( $n=5-7$ per group per time point). Adrenalectomy had no effect on the rhythm of PER2 expression in the SCN, whereas it completely blunted the rhythm in the BNST-OV.

SCN (Watts et al., 1987; Yamazaki et al., 1998). The BNST-OV projects to virtually all other subregions of the BNST as well as to several brain regions outside the BNST (Dong et al., 2001). The latter include the central nucleus of the amygdala (CEA), the tuberal region of the lateral hypothalamus, the parabrachial nucleus (PB), and the nucleus of the solitary tract (NTS), all of which have been shown to play important roles in controlling autonomic responses to homeostatic challenge and fear stimuli (Dong et al., 2001). In addition, the BNST-OV has been shown to innervate the substantia innominata and nucleus accumbens, both of which play key roles in the control of motivated behaviors driven by drugs and other incentive stimuli as well as in the control of behaviors driven by homeostatic needs, such as food and water intake. Furthermore, the BNST-OV has been shown to receive afferents from many other subregions of the BNST and from the CEA, NTS, PB, locus coeruleus, dorsal raphe nucleus, ventral tegmental area, postpiriform transition cortical area, and insular cortex (Dong et al., 2001). These neural connections, taken together with the evidence of glucocorticoid sensitivity, place the BNST-OV in a unique position to integrate stress and homeostatic and incentive stimuli, as well as to coordinate physiological responses and behaviors that are engaged by these stimuli. The present finding that the BNST-OV contains subordinate 
circadian clock cells provides a mechanism whereby the SCN could impose local circadian control over gene expression and neural activity and thereby affect information processing within the BNST as well as influence activity in neural circuits downstream from the BNST. Finally, the possibility that the putative clock cells of the BNST-OV might be sensitive to stress-, drug-, and food-related stimuli provides a mechanism whereby such stimuli can affect circadian rhythms downstream from the SCN clock.

\section{References}

Abe M, Herzog ED, Yamazaki S, Straume M, Tei H, Sakaki Y, Menaker M, Block GD (2002) Circadian rhythms in isolated brain regions. J Neurosci 22:350-356.

Aguilar-Roblero R, Drucker-Colin R, Moore RY (1992) Behavioral and morphological studies of fetal neural transplants into SCN-lesioned rats. Chronobiol Int 9:278-296.

Balsalobre A (2002) Clock genes in mammalian peripheral tissues. Cell Tissue Res 309:193-199.

Balsalobre A, Marcacci L, Schibler U (2000a) Multiple signaling pathways elicit circadian gene expression in cultured rat-1 fibroblasts. Curr Biol 10:1291-1294.

Balsalobre A, Brown SA, Marcacci L, Tronche F, Kellendonk C, Reichardt HM, Schutz G, Schibler U (2000b) Resetting of circadian time in peripheral tissues by glucocorticoid signaling. Science 289:2344-2347.

Beaulé C, Amir S (2003) The eyes suppress a circadian rhythm of fos expression in the suprachiasmatic nucleus in the absence of light. Neuroscience 121:253-257.

Beaulé C, Arvanitogiannis A, Amir S (2001) Light suppresses Fos expression in the shell region of the suprachiasmatic nucleus at dusk and dawn: implications for photic entrainment of circadian rhythms. Neuroscience 106:249-254.

Beaulé C, Houle LM, Amir S (2003) Expression profiles of PER2 immunoreactivity within the shell and core regions of the rat suprachiasmatic nucleus: lack of effect of photic entrainment and disruption by constant light. J Mol Neurosci 21:133-148.

Bittman EL, Doherty L, Huang L, Paroskie A (2003) Period gene expression in mouse endocrine tissues. Am J Physiol Regul Integr Comp Physiol 285:R561-569.

Bonaz B, De Giorgio R, Tache Y (1993) Peripheral bombesin induces c-fos protein in the rat brain. Brain Res 600:353-357.

Buijs RM, Kalsbeek A (2001) Hypothalamic integration of central and peripheral clocks. Nat Rev Neurosci 2:521-526.

Carr KD, Kutchukhidze N (2000) Effect of chronic food restriction on Foslike immunoreactivity (FLI) induced in rat brain regions by intraventricular MK-801. Brain Res 873:283-286.

Carr KD, Park TH, Zhang Y, Stone EA (1998) Neuroanatomical patterns of Fos-like immunoreactivity induced by naltrexone in food-restricted and ad libitum fed rats. Brain Res 779:26-32.

Casada JH, Dafny N (1991) Restraint and stimulation of bed nucleus of the stria terminalis produce similar stress-like behaviors. Brain Res Bull 27:207-212.

Cooper HM, Parvopassu F, Herbin M, Magnin M (1994) Neuroanatomical pathways linking vision and olfaction in mammals. Psychoneuroendocrinology 19:623-639.

Damiola F, Le Minh N, Preitner N, Kornmann B, Fleury-Olela F, Schibler U (2000) Restricted feeding uncouples circadian oscillators in peripheral tissues from the central pacemaker in the suprachiasmatic nucleus. Genes Dev 14:2950-2961.

Davis M, Walker DL, Lee Y (1997) Amygdala and bed nucleus of the stria terminalis: differential roles in fear and anxiety measured with the acoustic startle reflex. Philos Trans R Soc Lond B Biol Sci 352:1675-1687.

Day HE, Curran EJ, Watson SJ Jr, Akil H (1999) Distinct neurochemical populations in the rat central nucleus of the amygdala and bed nucleus of the stria terminalis: evidence for their selective activation by interleukin1beta. J Comp Neurol 413:113-128.

Day HE, Badiani A, Uslaner JM, Oates MM, Vittoz NM, Robinson TE, Watson Jr SJ, Akil H (2001) Environmental novelty differentially affects c-fos mRNA expression induced by amphetamine or cocaine in subregions of the bed nucleus of the stria terminalis and amygdala. J Neurosci 21:732-740. de la Iglesia HO, Meyer J, Schwartz WJ (2003) Lateralization of circadian pacemaker output: activation of left- and right-sided luteinizing hormone-releasing hormone neurons involves a neural rather than a humoral pathway. J Neurosci 23:7412-7414.

Dong HW, Petrovich GD, Watts AG, Swanson LW (2001) Basic organization of projections from the oval and fusiform nuclei of the bed nuclei of the stria terminalis in adult rat brain. J Comp Neurol 436:430-455.

Edelstein K, Amir S (1999) The intergeniculate leaflet does not mediate the disruptive effects of constant light on circadian rhythms in the rat. Neuroscience 90:1093-1101.

Edelstein K, Pfaus JG, Rusak B, Amir S (1995) Neonatal monosodium glutamate treatment prevents effects of constant light on circadian temperature rhythms of adult rats. Brain Res 675:135-142.

Engstrom L, Engblom D, Blomqvist A (2003) Systemic immune challenge induces preproenkephalin gene transcription in distinct autonomic structures of the rat brain. J Comp Neurol 462:450-461.

Erb S, Salmaso N, Rodaros D, Stewart J (2001) A role for the CRFcontaining pathway from central nucleus of the amygdala to bed nucleus of the stria terminalis in the stress-induced reinstatement of cocaine seeking in rats. Psychopharmacology (Berl) 158:360-365.

Field MD, Maywood ES, O’Brien JA, Weaver DR, Reppert SM, Hastings MH (2000) Analysis of clock proteins in mouse SCN demonstrates phylogenetic divergence of the circadian clockwork and resetting mechanisms. Neuron 25:437-447.

Figueiredo H, Bodie BL, Tauchi M, Dolgas CM, Herman JP (2003) Stress integration following acute and chronic predator stress: differential activation of central stress circuitry and sensitization of the hypothalamopituitary-adrenocortical axis. Endocrinology 144:5249-5258.

Fink JS, Smith GP (1980) Mesolimbicocortical dopamine terminal fields are necessary for normal locomotor and investigatory exploration in rats. Brain Res 199:359-384.

Gillette MU, Reppert SM (1987) The hypothalamic suprachiasmatic nuclei: circadian patterns of vasopressin secretion and neuronal activity in vitro. Brain Res Bull 19:135-139.

Gray TS (1993) Amygdaloid CRF pathways. Role in autonomic, neuroendocrine, and behavioral responses to stress. Ann NY Acad Sci 697:53-60.

Hastings MH, Reddy AB, Maywood ES (2003) A clockwork web: circadian timing in brain and periphery, in health and disease. Nat Rev Neurosci 4:649-661.

Inouye ST, Kawamura H (1979) Persistence of circadian rhythmicity in a mammalian hypothalamic "island" containing the suprachiasmatic nucleus. Proc Natl Acad Sci USA 76:5962-5966.

Itaya SK, Van Hoesen GW, Jenq CB (1981) Direct retinal input to the limbic system of the rat. Brain Res 226:33-42.

Kalsbeek A, Buijs RM (2002) Output pathways of the mammalian suprachiasmatic nucleus: coding circadian time by transmitter selection and specific targeting. Cell Tissue Res 309:109-118.

Klein D, Moore RY, Reppert SM, eds (1991) Suprachiasmatic nucleus: the mind's clock. Oxford: Oxford UP.

Kozicz T (2002) Met-enkephalin immunoreactive neurons recruited by acute stress are innervated by axon terminals immunopositive for tyrosine hydroxylase and dopamine-alpha-hydroxylase in the anterolateral division of bed nuclei of the stria terminalis in the rat. Eur J Neurosci 16:823-835.

Kriegsfeld LJ, Korets R, Silver R (2003) Expression of the circadian clock gene Period 1 in neuroendocrine cells: an investigation using mice with a Per1::GFP transgene. Eur J Neurosci 17:212-220.

Leak RK, Moore RY (2001) Topographic organization of suprachiasmatic nucleus projection neurons. J Comp Neurol 433:312-334.

Lechner SM, Valentino RJ (1999) Glucocorticoid receptor-immunoreactivity in corticotrophin-releasing factor afferents to the locus coeruleus. Brain Res 816:17-28.

Lee HS, Nelms JL, Nguyen M, Silver R, Lehman MN (2003) The eye is necessary for a circadian rhythm in the suprachiasmatic nucleus. Nat Neurosci 6:111-112.

LeSauter J, Lehman MN, Silver R (1996) Restoration of circadian rhythmicity by transplants of SCN "micropunches". J Biol Rhythms 11:163-171.

Li BH, Rowland NE (1995) Effects of vagotomy on cholecystokinin- and dexfenfluramine-induced Fos-like immunoreactivity in the rat brain. Brain Res Bull 37:589-593.

Li H, Satinoff E (1998) Fetal tissue containing the suprachiasmatic nucleus 
restores multiple circadian rhythms in old rats. Am J Physiol 275:R1735-1744.

Liu C, Reppert SM (2000) GABA synchronizes clock cells within the suprachiasmatic circadian clock. Neuron 25:123-128.

Loewy AD (1991) Forebrain nuclei involved in autonomic control. Prog Brain Res 87:253-268.

Makino S, Gold PW, Schulkin J (1994) Effects of corticosterone on CRH mRNA and content in the bed nucleus of the stria terminalis: comparison with the effects in the central nucleus of the amygdala and the paraventricular nucleus of the hypothalamus. Brain Res 657:141-149.

Moore RY, Speh JC (1993) GABA is the principal neurotransmitter of the circadian system. Neurosci Lett 150:112-116.

Moore RY, Speh JC, Leak RK (2002) Suprachiasmatic nucleus organization. Cell Tissue Res 309:89-98.

Mrosovsky N (1996) Locomotor activity and non-photic influences on circadian clocks. Biol Rev Camb Philos Soc 71:343-372.

Nijsen MJ, Croiset G, Diamant M, De Wied D, Wiegant VM (2001) CRH signaling in the bed nucleus of the stria terminalis is involved in stressinduced cardiac vagal activation in conscious rats. Neuropsychopharmacology 24:1-10.

Nuesslein-Hildesheim B, O’Brien JA, Ebling FJ, Maywood ES, Hastings MH (2000) The circadian cycle of mPER clock gene products in the suprachiasmatic nucleus of the Siberian hamster encodes both daily and seasonal time. Eur J Neurosci 12:2856-2864.

Oishi K, Sakamoto K, Okada T, Nagase T, Ishida N (1998) Humoral signals mediate the circadian expression of rat period homologue (rPer2) mRNA in peripheral tissues. Neurosci Lett 256:117-119.

Pompei P, Riftina F, McEwen BS (1995) Effect of adrenal steroids on preproneurokinin-A gene expression in discrete regions of the rat brain. Brain Res Mol Brain Res 33:209-216.

Ralph MR, Foster RG, Davis FC, Menaker M (1990) Transplanted suprachiasmatic nucleus determines circadian period. Science 247:975-978.

Reddy AB, Field MD, Maywood ES, Hastings MH (2002) Differential resynchronization of circadian clock gene expression within the suprachiasmatic nuclei of mice subjected to experimental jet lag. J Neurosci 22:7326-7330.

Reppert SM (2000) Cellular and molecular basis of circadian timing in mammals. Semin Perinatol 24:243-246.

Reppert SM, Weaver DR (2001) Molecular analysis of mammalian circadian rhythms. Annu Rev Physiol 63:647-676.

Reppert SM, Weaver DR (2002) Coordination of circadian timing in mammals. Nature 418:935-941.

Rosenfeld P, Van Eekelen JA, Levine S, De Kloet ER (1988) Ontogeny of the type 2 glucocorticoid receptor in discrete rat brain regions: an immunocytochemical study. Brain Res 470:119-127.

Rosenfeld P, van Eekelen JA, Levine S, de Kloet ER (1993) Ontogeny of corticosteroid receptors in the brain. Cell Mol Neurobiol 13:295-319.

Sakamoto K, Nagase T, Fukui H, Horikawa K, Okada T, Tanaka H, Sato K, Miyake Y, Ohara O, Kako K, Ishida N (1998) Multitissue circadian expression of rat period homolog (rPer2) mRNA is governed by the mammalian circadian clock, the suprachiasmatic nucleus in the brain. J Biol Chem 273:27039-27042.

Schibler U, Sassone-Corsi P (2002) A web of circadian pacemakers. Cell 111:919-922.

Schwartz WJ, Davidsen LC, Smith CB (1980) In vivo metabolic activity of a putative circadian oscillator, the rat suprachiasmatic nucleus. J Comp Neurol 189:157-167.

Shearman LP, Sriram S, Weaver DR, Maywood ES, Chaves I, Zheng B, Kume K, Lee CC, van der Horst GT, Hastings MH, Reppert SM (2000) Inter- acting molecular loops in the mammalian circadian clock. Science 288:1013-1019.

Shieh KR (2003) Distribution of the rhythm-related genes rPERIOD1, rPERIOD2, and rCLOCK in the rat brain. Neuroscience 118:831-843.

Silver R, LeSauter J, Tresco PA, Lehman MN (1996) A diffusible coupling signal from the transplanted suprachiasmatic nucleus controlling circadian locomotor rhythms. Nature 382:810-813.

Sollars PJ, Pickard GE (1998) Restoration of circadian behavior by anterior hypothalamic grafts containing the suprachiasmatic nucleus: graft/host interconnections. Chronobiol Int 15:513-533.

Stefanova N, Ovtscharoff W (2000) Sexual dimorphism of the bed nucleus of the stria terminalis and the amygdala. Adv Anat Embryol Cell Biol 158:1-78.

Stephan FK, Swann JM, Sisk CL (1979) Anticipation of 24-hr feeding schedules in rats with lesions of the suprachiasmatic nucleus. Behav Neural Biol 25:346-363.

Stokkan KA, Yamazaki S, Tei H, Sakaki Y, Menaker M (2001) Entrainment of the circadian clock in the liver by feeding. Science 291:490-493.

Sudo M, Sasahara K, Moriya T, Akiyama M, Hamada T, Shibata S (2003) Constant light housing attenuates circadian rhythms of mPer2 mRNA AND mPER2 protein expression in the suprachiasmatic nucleus of mice. Neuroscience 121:493-499.

Sun N, Cassell MD (1993) Intrinsic GABAergic neurons in the rat central extended amygdala. J Comp Neurol 330:381-404.

Szafarczyk A, Ixart G, Alonso G, Malaval F, Nouguier-Soule J, Assenmacher I (1983) CNS control of the circadian adrenocortical rhythm. J Steroid Biochem 19:1009-1015.

Van de Kar LD, Blair ML (1999) Forebrain pathways mediating stressinduced hormone secretion. Front Neuroendocrinol 20:1-48.

Wakamatsu H, Yoshinobu Y, Aida R, Moriya T, Akiyama M, Shibata S (2001) Restricted-feeding-induced anticipatory activity rhythm is associated with a phase-shift of the expression of mPer1 and mPer2 mRNA in the cerebral cortex and hippocampus but not in the suprachiasmatic nucleus of mice. Eur J Neurosci 13:1190-1196.

Walker CD, Toufexis DJ, Burlet A (2001) Hypothalamic and limbic expression of CRF and vasopressin during lactation: implications for the control of ACTH secretion and stress hyporesponsiveness. Prog Brain Res 133:99-110.

Walker DL, Toufexis DJ, Davis M (2003) Role of the bed nucleus of the stria terminalis versus the amygdala in fear, stress, and anxiety. Eur J Pharmacol 463:199-216.

Watts AG, Sanchez-Watts G (1995) Region-specific regulation of neuropeptide mRNAs in rat limbic forebrain neurones by aldosterone and corticosterone. J Physiol (Lond) 484:721-736.

Watts AG, Swanson LW, Sanchez-Watts G (1987) Efferent projections of the suprachiasmatic nucleus: I. Studies using anterograde transport of Phaseolus vulgaris leucoagglutinin in the rat. J Comp Neurol 258:204-229.

Welsh DK, Logothetis DE, Meister M, Reppert SM (1995) Individual neurons dissociated from rat suprachiasmatic nucleus express independently phased circadian firing rhythms. Neuron 14:697-706.

Yamazaki S, Kerbeshian MC, Hocker CG, Block GD, Menaker M (1998) Rhythmic properties of the hamster suprachiasmatic nucleus in vivo. J Neurosci 18:10709-10723.

Yamazaki S, Numano R, Abe M, Hida A, Takahashi R, Ueda M, Block GD, Sakaki Y, Menaker M, Tei H (2000) Resetting central and peripheral circadian oscillators in transgenic rats. Science 288:682-685.

Zheng B, Larkin DW, Albrecht U, Sun ZS, Sage M, Eichele G, Lee CC, Bradley A (1999) The mPer2 gene encodes a functional component of the mammalian circadian clock. Nature 400:169-173. 